\title{
A Review of the NASA MLAS Flight Demonstration
}

\author{
Anthony P. Taylor ${ }^{1}$, Christopher Kelley ${ }^{2}$, Eldred Magner ${ }^{3}$, David Peterson ${ }^{4}$ \\ Airborne System, Santa Ana, CA, 92704 \\ Jeffrey Hahn ${ }^{5}$ \\ Jacobs Technology - Engineering and Science Contract Group, Houston, TX, 77058 \\ and \\ Daniel Yuchnovicz ${ }^{6}$ \\ NASA Engineering and Safety Center, Hampton, VA, 23681
}

The NASA Engineering and Safety Center (NESC) has tested the Max Launch Abort System (MLAS) as a risk-mitigation design should problems arise with the baseline Orion spacecraft launch abort design. The Max in MLAS is not Maximum, but rather dedicated to Max Faget, the renowned NASA Spacecraft designer. In July 2009, the mission was flown, with great success, from the NASA Wallops Flight Facility.

The MLAS flight test vehicle prototype consists of a boost skirt, coast skirt, and the MLAS fairing itself, which houses an Orion Command Module (CM) boilerplate. The objective of the MLAS flight test is to reorient the fairing with the $\mathrm{CM}$, weighing approximately 29,000 lbs and traveling $290 \mathrm{fps}, 180$ degrees to an orientation suitable for the release of the CM during a pad abort or low altitude abort. The boost and coast skirts provide the necessary thrust and stability to establish the flight test conditions and are released prior to the reorientation of the fairing. A secondary test objective after successful release of the $\mathrm{CM}$ from the fairing is to demonstrate the removal of the $\mathrm{CM}$ forward bay cover (FBC) with the $\mathrm{CM}$ drogue parachutes, and subsequent deployment of the $\mathrm{CM}$ main parachutes attached to the $\mathrm{FBC}$.

Although multiple parachute deployments are used in the MLAS flight test vehicle to complete its objective, there are only two parachute types employed in the flight test. Five of the nine parachutes used for MLAS are $27.6 \mathrm{ft}$ DO ribbon parachutes already proven as a spin/stall parachute for military aircraft, and the remaining four are G-12 cargo parachutes modified for increased strength and reefing.

This paper presents an overview of the $27.6 \mathrm{ft}$ DO ribbon parachute system employed on the MLAS flight test vehicle for coast skirt separation, fairing reorientation, and as CM drogue parachutes. Discussion will include: the process used to select this design; descriptions of all components of the parachute system; the minor modifications necessary to adapt the parachute to the MLAS program; the techniques used to analyze the parachute for the multiple roles it performs including discussions of how the evolution of the program affected parachute usage and analysis; a summary of the results of the highly successful flight test, including video of the flight test; and an overview of the subsequent post-test analysis.

\footnotetext{
${ }^{1}$ Technical Director, Space Market, 3000 West Segerstrom Ave., CA 92704, AIAA Associate Fellow.

${ }^{2}$ Design Lead, Engineering Services, 3000 Segerstrom Ave, Santa Ana, CA 92704, AIAA Member.

${ }^{3}$ Design Engineer, Engineering Services, 3000 Segerstrom Ave, Santa Ana, CA 92704, AIAA Member.

${ }^{4}$ Systems Analyst, Engineering Services, 3000 Segerstrom Ave, Santa Ana, CA 92704, Non-member.

${ }^{5}$ Project Manager, Scientific, Engineering, and Analysis Services, 2224 Bay Area Blvd., MS JEB252, Houston, TX, 77058, Professional Member.

${ }^{6}$ Systems Engineer, NESC Systems Engineering Office, MS 112 NASA Langley Research Center, Hampton, VA 23681, Non-member.
} 


\section{Nomenclature}

$\begin{array}{ll}\text { AoA } & =\text { Angle of Attack } \\ C_{D} & =\text { drag coefficient } \\ C E V & =\text { Crew Exploration Vehicle } \\ C O T S & =\text { Commercial Off The Shelf } \\ C P A S & =\text { CEV Parachute Assembly System } \\ C M & =\text { Crew Module } \\ D_{0} & =\text { parachute reference diameter } \\ D T V & =\text { Drop Test Vehicle } \\ F B C & =\text { Forward Bay Cover } \\ F D U & =\text { Flight Design Unit } \\ I M L & =\text { Inner Mold Line } \\ K A I & =\text { Korea Aerospace Industries, Ltd. } \\ L P D & =\text { Landing Parachute Demonstration } \\ M L A S & =\text { Max Launch Abort System } \\ N E S C & =\text { NASA Engineering and Safety Center } \\ O M L & =\text { Outer Mold Line } \\ R F P & =\text { Request for Proposal } \\ S_{O} & =\text { parachute reference area } \\ S_{\infty} & =\text { required free-stream parachute reference area } \\ S R A L T & =\text { Short Range Air Launch Target } \\ T P S & =\text { Thermal Protective System } \\ V P C R & =\text { Variable Porosity Conical Ribbon }\end{array}$

\section{MLAS System Description}

$\mathrm{T}$ HE flight test of the MLAS system is a pad-abort type test. On initiation of the unguided, passively stabilized vehicle test, four solid rocket motors installed in the boost skirt are ignited to place the system in a launch abort trajectory. After rocket burn-out, the boost skirt falls away from the fairing. On the objective system, there would be no boost skirt, the rockets would be housed in the fairing above the $\mathrm{CM}$ and remain with the fairing. The flight test is designed to be a rapid evaluation of the MLAS concept of operation, and some features of the objective system have been modified on the flight test system to reduce complexity without significantly impacting the goals of the test. The NASA Engineering and Safety Center (NESC) was challenged to design, build, and fly the MLAS flight test in a short period of time while minimizing risk. The first goal drove NESC to determine reasonable tradeoffs between fidelity to the objective system and ability to meet the time goal. One of the significant methods employed to try to meet the risk mitigation goal was the use commercial off the shelf (COTS) hardware or flightproven designs wherever possible.

After the boost skirt is jettisoned, there is a period of stable coast. Here again there is a difference between the flight test system and objective system. On the objective system, grid fins are extended at the aft end of the fairing on system initiation to provide stability. On the flight test system, there are fixed fins on the boost skirt, and there is a coast skirt also not present on the objective system with fixed fins to provide stability. At the end of the coast phase, a mortar located inside the coast skirt deploys a $27.6 \mathrm{ft} \mathrm{D}_{0}$ Variable Porosity Conical Ribbon (VPCR) drogue parachute directly aft of the vehicle. The coast skirt is separated from the fairing 0.3 seconds after the mortar is fired, so that the coast skirt is free before the parachute inflates. The drogue parachute aids in the quick separation of the coast skirt from the fairing.

Three seconds after coast skirt separation, two $27.6 \mathrm{ft} \mathrm{D}_{0}$ VPCR drogues are mortar deployed at an angle $20^{\circ}$ down (aft) from perpendicular to the vehicle vertical axis. On the objective system, the grid fins would be jettisoned just prior to the firing of these reorientation drogue mortars. These drogues are identical to the drogue used to separate the coast skirt, and are used to reorient the fairing to a stable orientation with the CM heat shield down. At this point, the $\mathrm{CM}$ is released and two more $27.6 \mathrm{ft} \mathrm{D}_{0}$ VPCR drogues are deployed via a static line to simulate the Orion Crew Exploration Vehicle (CEV) Parachute Assembly System (CPAS) drogue parachutes. These drogues are connected to a simulated forward bay cover (FBC), to represent the CPAS Flight Design Unit configuration. As the $\mathrm{CM}$ nears the water, the FBC is separated from the CM and four modified G-12 parachutes are deployed from the FBC in a similar manner to the original CPAS Flight Design Unit (FDU) baseline. These four G-12's simulate the three CPAS $116 \mathrm{ft} \mathrm{D}_{0}$ ringsail parachutes. Figure 1, provided by NASA, graphically shows the differences between the objective system and flight test system concepts of operation through CM separation. 


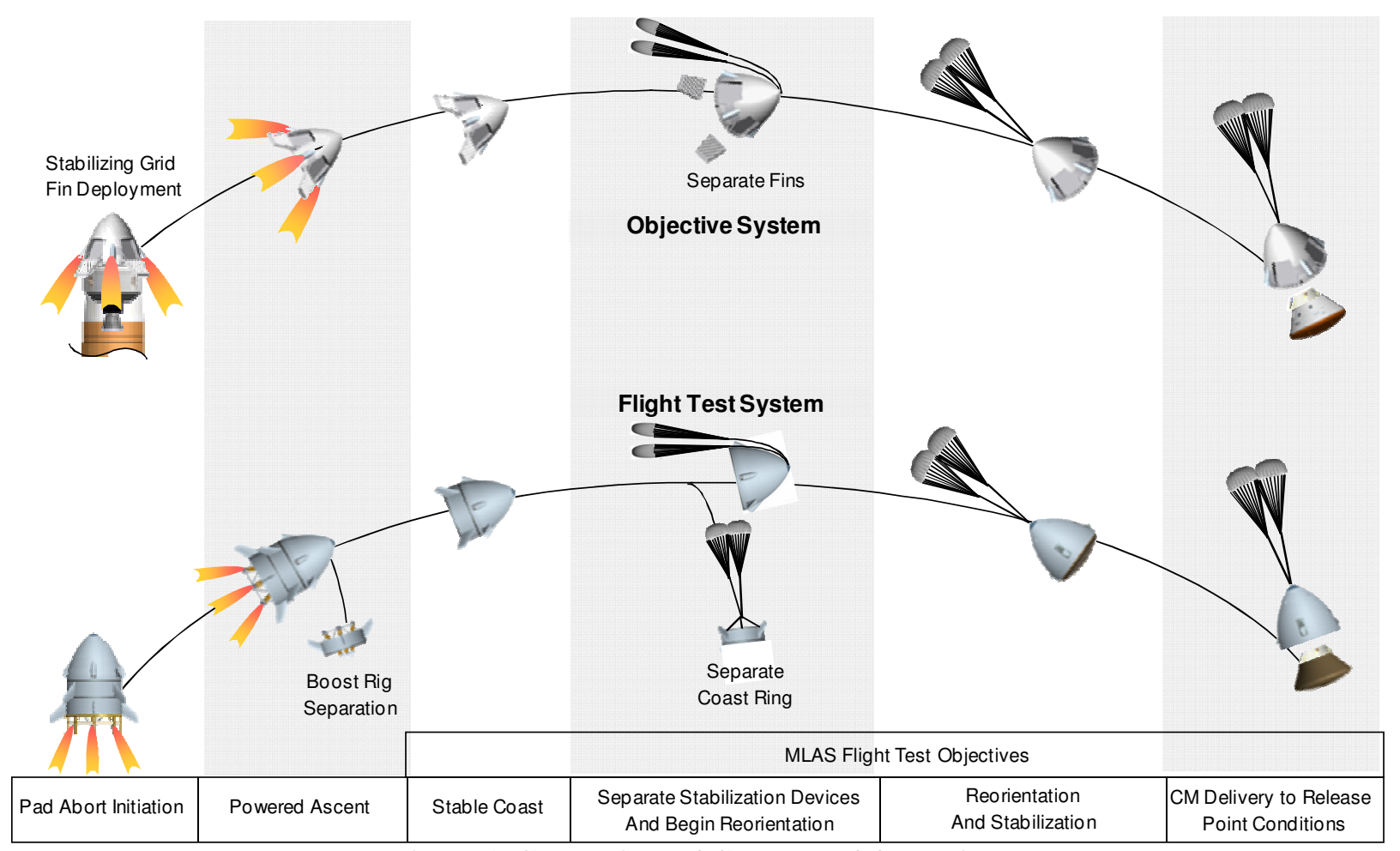

Figure 1. Comparison of Concepts of Operation

\section{Parachute Selection}

The original MLAS Request for Proposal (RFP) only addressed the reorientation parachutes and requested two mortar-deployed parachutes with a drag area $\left(\mathrm{C}_{\mathrm{D}} \mathrm{S}_{\infty}\right)$ of $258 \mathrm{ft}^{2}$ each. In order to correctly size the parachute, this required drag area was adjusted to account for the planform drag coefficient and the forebody wake effects. The measured planform drag coefficient (CD) for the Airborne Systems VPCR parachute is 0.55 . The required freestream reference area $\left(S_{\infty}\right)$ is calculated with Equation 1.

$$
S_{\infty}=\frac{C_{D} S_{\infty}}{C_{D}}=\frac{258}{0.55}=469 f t^{2}
$$

Using a design trailing distance of 5 body diameters, the drag loss due to forebody wake is estimated at $20 \%$. The free-stream reference area is then corrected to the required parachute reference area $\left(S_{0}\right)$ and the required parachute reference diameter is determined with Equation 2 and Equation 3.

$$
\begin{aligned}
& S_{0}=\frac{S_{\infty}}{0.80}=586.4 f t^{2} \\
& D_{0}=\sqrt{\frac{4 \cdot S_{0}}{\pi}}=27.3 f t
\end{aligned}
$$

Recalling the desire to use flight-proven hardware, a $27.6 \mathrm{ft} \mathrm{D}_{0}$ VPCR parachute that had been designed as a spin/stall recovery parachute for the F-22 and the Korea Aerospace Industries, Ltd. (KAI) T-50 aircraft was selected for the MLAS reorientation parachute.

Very minor modifications were required to adapt the T-50 parachute for use on the MLAS system. A single reefing stage of 53\% for 2 seconds was selected to manage the loads into the fairing and minimize the time required 
to achieve the full drag area. As the selected drogue did not incorporate reefing, the parachute design was modified to add a reefing system with dual cutters, as well as eliminate the load limiting fitting necessary for spin/stall installations, lengthen the parachute riser, and armor the section of riser that is exposed on the fairing between the mortar and confluence fitting. The mortar used to deploy the T-50 system was selected to deploy the MLAS parachutes. The mortar system was modified from the T-50 design to remove fairings and the load limiting fitting attachment. None of these relatively minor modifications impacted the flight-proven heritage of the drogue and mortar systems.

Initially, the use of drag devices similar to the objective system was envisioned to ensure separation of the coast skirt from the fairing. However, due to difficulties in developing a mechanism for symmetric deployment of the drag devices, the same parachute system used for the reorientation system was evaluated for use in separating the coast skirt, with the goal of creating a $200 \mathrm{ft}$ separation between the coast skirt and fairing within 3 seconds. It was found to be adequate for the task with the same reefing schedule used for the reorientation system. The only changes necessary were a re-clocking of the mortar breech to facilitate installation in the coast skirt, and length and material changes to the bridle legs.

For the CM drogue parachutes, the desire was to simulate the CPAS FDU system as closely as possible. Again looking for commonality across the system, the $27.6 \mathrm{ft} \mathrm{D}_{0}$ VPCR system was once again evaluated for use in this phase. It was found that mortar deployment of the drogues would not be practical for the boilerplate CM drogues due to the difficult issues involved with designing a FBC that could withstand mortar reaction loads and apex-first drogue deployment loads. It should be noted that an operational FBC design was not an objective of the MLAS Project. However, to simplify the FBC design, the drogues could be deployed via a static line attached to the fairing, and this was the configuration selected. Here the only modifications necessary were the addition of deployment bag bridles to facilitate the static line deployment of the bags, and the addition of grommet strips on the deployment bags to allow them to be tied together for deployment.

Since no spare set of CPAS $116 \mathrm{ft} \mathrm{D}_{0}$ ringsail main parachutes was available, NESC elected to use four off the shelf G-12 cargo parachutes with riser extensions to simulate the three CPAS mains. Evaluation of the loads expected to be encountered during deployment led to modification of the G-12 parachutes to include a single stage of reefing, reinforce the vent, and replace the suspension line to riser links with higher strength links. The reefing selected was $26.5 \%$ for 5 seconds based on experience gained in reefing the G-12 for the Short Range Air Launch Target (SRALT) program.

\section{Parachute System Description}

The 32 gore, $27.6 \mathrm{ft}$ D0 VPCR canopy and suspension lines are Nylon, with a Kevlar reefing line. A flat, twoplate titanium and steel confluence fitting is used to interface the parachute riser to the four bridle legs that connect the parachutes to the vehicle. The reorientation bridle legs are $15 \mathrm{ft}$ long and each is constructed of a single piece of Kevlar webbing formed into an 8 ply Möbius loop. These bridle legs are attached to the fairing using instrumented pins inserted into clevises. These pins, which are held in place with an anti-rotation fitting, contain internal strain gages which allow measurement of direction and magnitude of a radially applied load. Figure 2 presents the basic geometry of the CM, fairing and fairing re-orientation system and Figure 3 provides some additional dimensional details of the reorientation system.

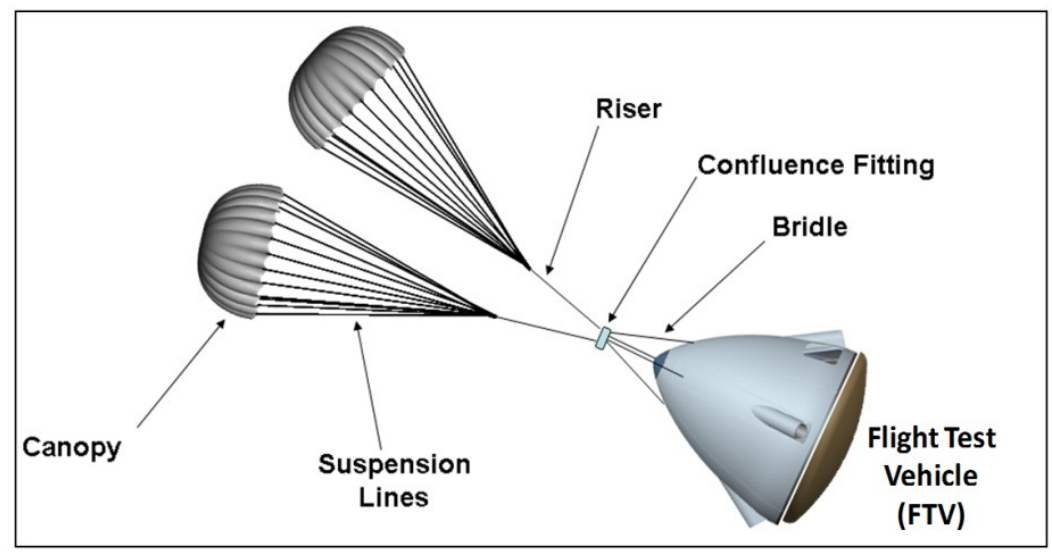

Figure 2. Fairing Re-orientation Parachutes

American Institute of Aeronautics and Astronautics 


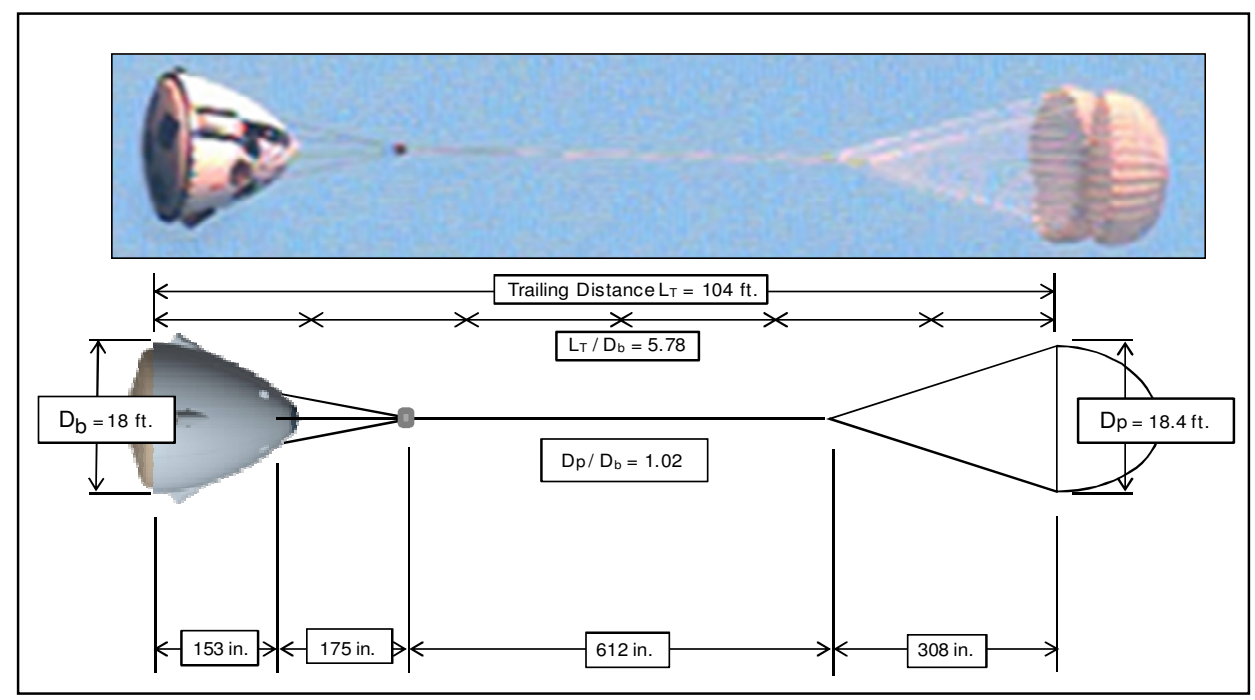

Figure 3. Re-orientation System Dimensions

The coast skirt separation system uses same the confluence fitting design. Since the coast skirt system utilizes a single parachute, only the inner two parachute fittings are used, and blank pins inserted in the other two. The coast skirt bridle legs are $25 \mathrm{ft}$ long and each is constructed of a single piece of Nylon webbing formed into an 8 ply Möbius loop. The coast skirt bridle legs are attached to mount points provided inside the coast skirt. Figure 4 provides an overview of the coast skirt separation parachute assembly. As discussed above, this feature was added later in the program and used the same parachute and mortar as the primary fairing re-orientation parachutes, as these were already procured and provided the required drag area.

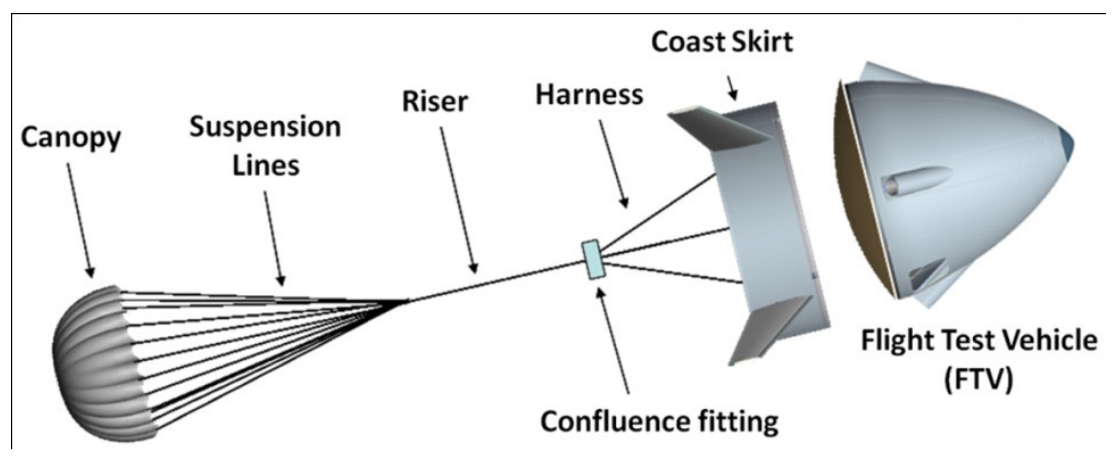

Figure 4. Coast Skirt and Parachute Separation System

The decision to use the $27.6 \mathrm{ft} \mathrm{D}_{0}$ VPCR parachutes as drogues for the boilerplate $\mathrm{CM}$ and tight vehicle integration schedule prevented the build of an additional titanium confluence fitting for use in the flight test. However, an existing three to two (3:2) confluence fitting that had been used for a heritage program was adapted with aluminum plates mimicking the parachute attachment features of the MLAS confluence fitting. Three $16 \mathrm{ft}$ long bridle legs are used for the FBC drogue system, each constructed of a single piece of Nylon webbing formed into a Möbius loop. The FBC drogue bridles are attached to mount points provided on top of the boilerplate FBC.

The modified G-12 parachutes used to simulate the CPAS main parachutes attach at a single point on the boilerplate CM, so no confluence fitting is necessary. This is similar to the current CPAS FDU baseline which has the main parachutes all attaching to a single gusset in the Orion forward bay. In order for the packed G-12 parachutes and the added riser extensions to fit inside the limited space afforded by the boilerplate FBC, their deployment bags were modified to be shorter, the external riser stowage was made more efficient, pressure packing techniques were used and beckets were installed on the deployment bags to facilitate attachment to the FBC. Figure 5 presents a view of the deployed main parachutes along with dimensional details. 


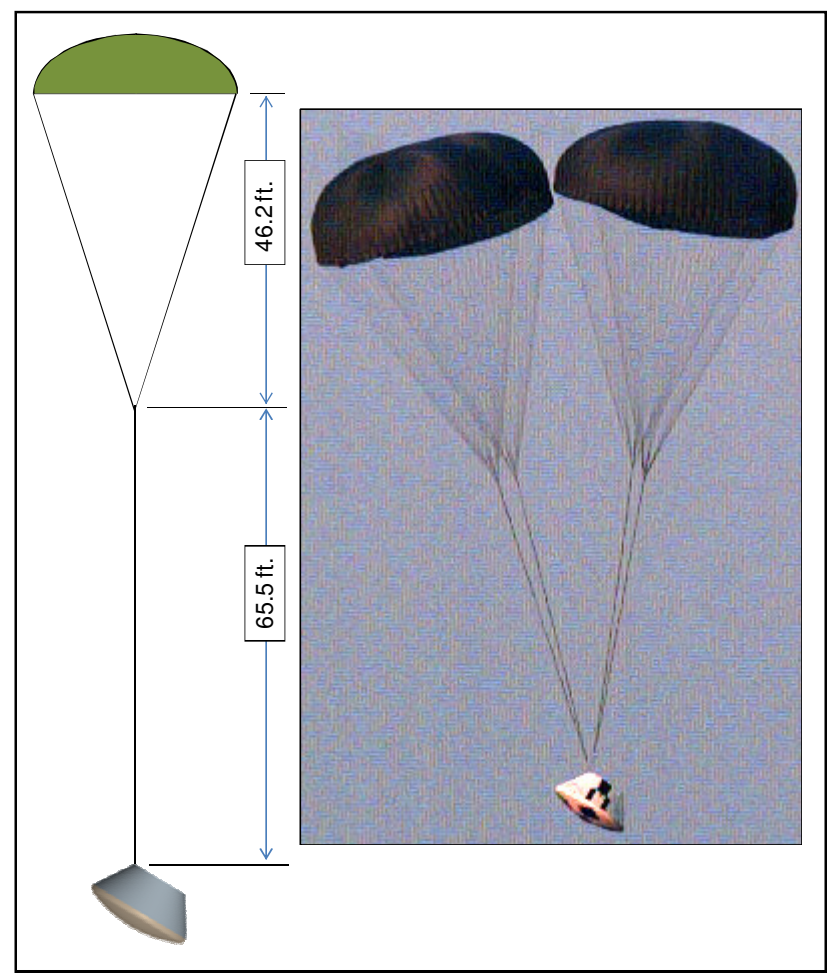

Figure 5. Main Parachute System Dimensions

\section{Integration of Parachutes into MLAS System}

Integration of the parachutes into the MLAS coast skirt, fairing, and CM boilerplate presented some technical challenges to ensure orderly deployment of the parachutes. Most notable were stowage issues.

The coast skirt stowage was the most straightforward of the three. The coast skirt is essentially a hollow tube with stabilization fins. Therefore, it requires a multi-point bridle and confluence fitting as described above. The bridle leg length was determined by the requirement for the bridle legs to stow along the inside wall of the coast skirt, and to reduce the cosine amplification of the bridle leg force. No stowage across the coast skirt was possible due to the fact that the boost skirt motor cage extended through the coast skirt to contact the boilerplate CM. Figure 6 below shows the mortar, confluence fitting, and some of the bridle leg stowage in the coast skirt.

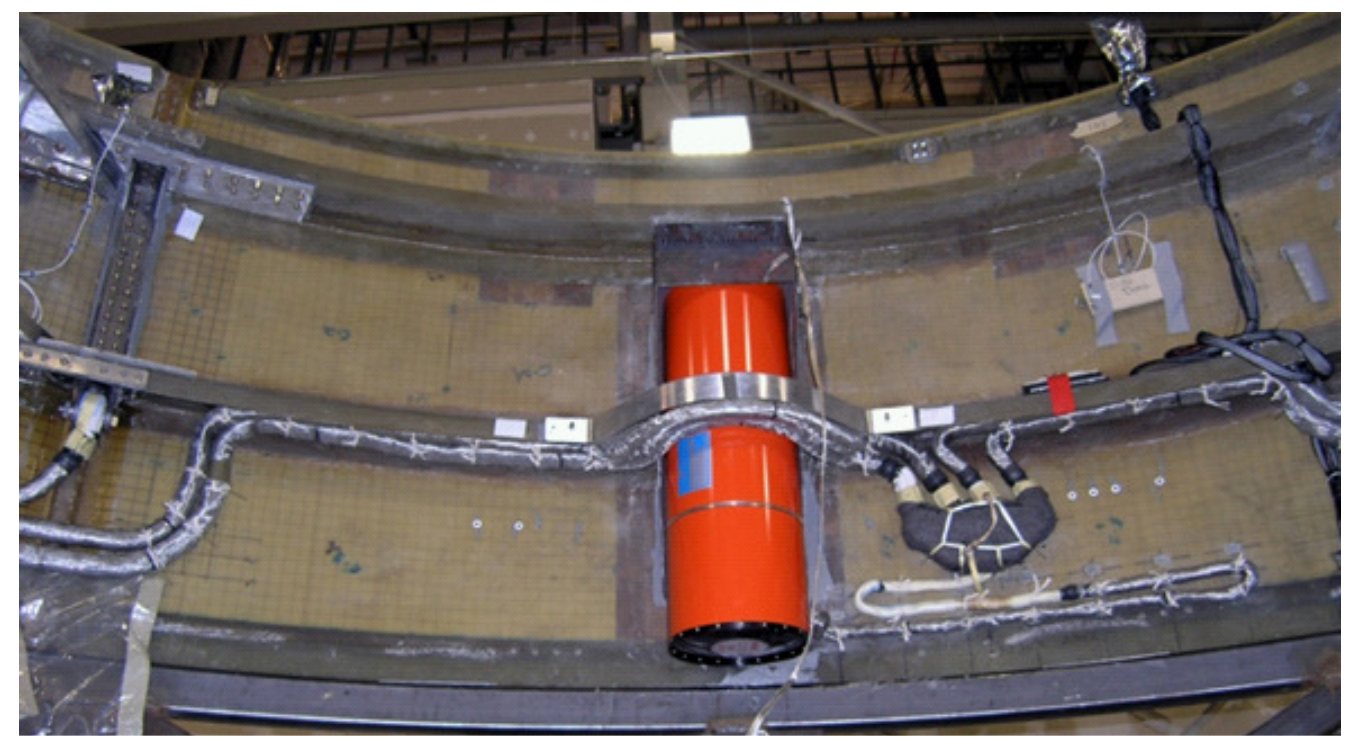

Figure 6. Coast Skirt Mortar and Bridle Rigging

American Institute of Aeronautics and Astronautics 
The coast skirt bridle legs were held in place with $801 \mathrm{lb}$ cotton tape routed through Click Bonds ${ }^{\circledR}$ attached every 6 inches to the underside of the lower stiffening ring and the inner mold line (IML) of the coast skirt. The confluence fitting, seen in Figure 6 covered in protective felt, was attached to the IML with a high strength nylon donut tie. Redundant cut knife lanyards were attached to the coast skirt drogue riser to free the confluence as the drogue deployed.

For the fairing, initially it was planned that everything but the mortars would be stowed inside the fairing nose cone and the bridles would attach to a 3 points along the diameter of the nose cone. After some analysis, the diameter of the nose cone attachment radius was found to likely be too small to successfully dampen the pitch rate after re-orientation. Additionally, the confluence and bridle legs could not have been erected until the drogues were inflating, resulting in large snatch forces as the confluence was lifted and re-accelerated to the vehicle velocity.

Eventually it was found that if the confluence fitting was stowed on the side of the vehicle, two of the bridles could be rigged to be fully extended along the outer mold line (OML) of the vehicle between their attach points and the confluence fitting. An illustration of the rigging is shown in Figure 7. Since the drogues will not develop force until they are aligned with the freestream, and therefore pulling directly on the stretched-out bridle legs, the snatch force on the confluence is eliminated with this configuration. Additionally the 3 point attach became a 4 point attach, and the attach points moved further away from the nose of the vehicle to a point where sufficient leverage existed to dampen the pitch rate. In the figure it can be seen that the attach fittings are located just above the motor troughs where the motors would be located in the objective system.

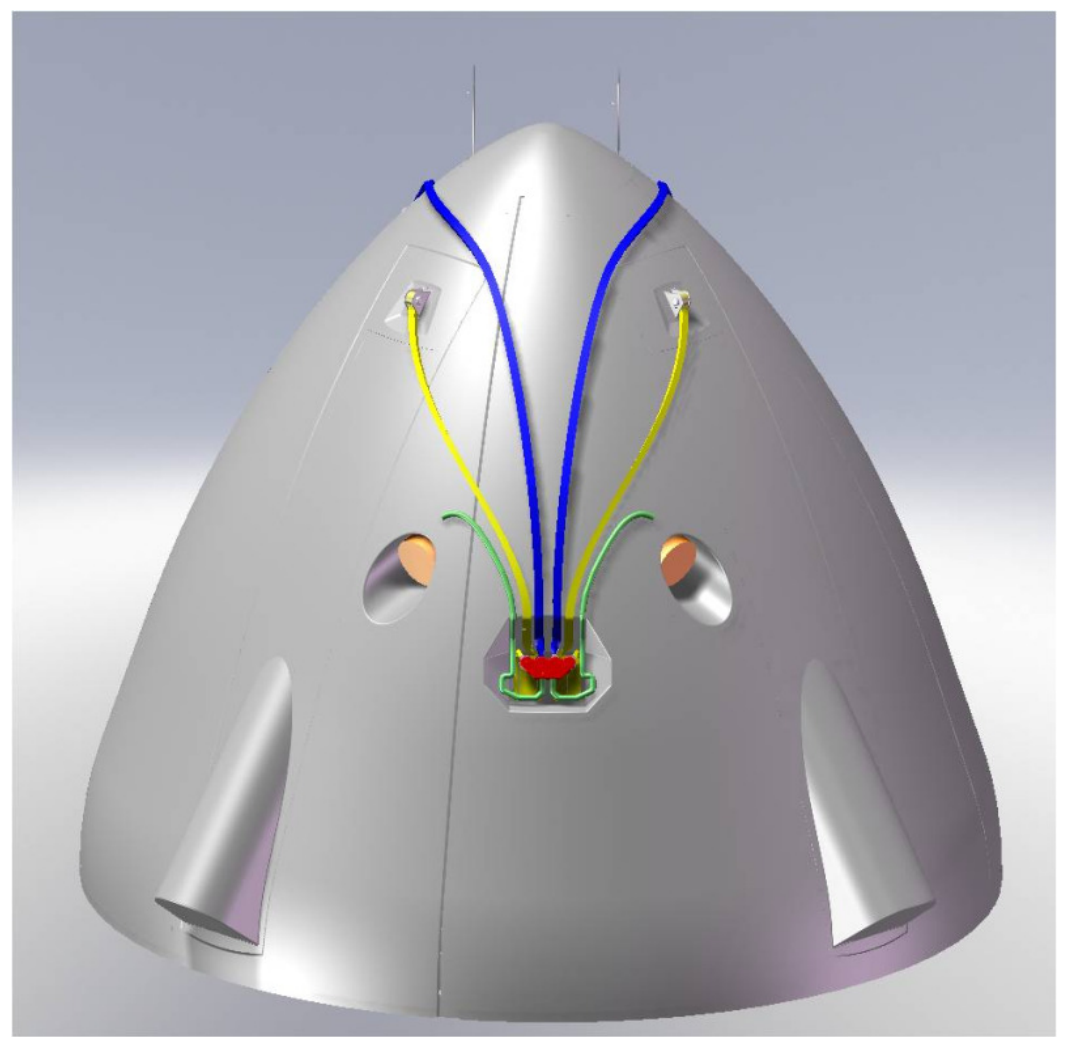

Figure 7. MLAS Fairing with Bridle Leg Routing

The entire length of the bridle legs are covered with stainless steel braided sleeving to protect the bridle legs during deployment. The mortars are mounted to the sides of the motor troughs, clocking the mortars 90 degrees apart. In addition to taking advantage of available structure, this has the advantage of ensuring that only one mortar could be fired directly into the wind should the pitch attitude be severely off-nominal at mortar fire.

Attachment of the bridle legs to the fairing was also a challenge. The desired solution would be to locate the bridle legs in channels molded into the fairing and protect them with some form of thermal protective system (TPS). However, the fairing molds were too far along in production to incorporate the channels The alternative solution selected was to attach the bridle legs to the outside of the fairing by adhering Click Bonds ${ }^{\circledR}$ to the fairing and tying the bridle legs to the Click Bonds ${ }^{\circledR}$ with $80 \mathrm{lb}$ cotton tape. 
The simulation of the CPAS parachute system is referred to in the MLAS flight test program as the Landing Parachute Demonstration (LPD). The drogue parachutes used for this phase are, as previously discussed, identical to the parachutes used for coast skirt separation and reorientation, except that they are installed onto the top of the boilerplate FBC and deployed via dual static lines attached inside the reorientation fairing. The drogue parachute deployment bags were tied together, and attached to low profile rails provided on the top of the FBC. The confluence fitting for these drogues is attached to the drogue deployment bags to ensure it is lifted with drogues on deployment. Photos of the installation of the drogues and bridle legs on top of the FBC are shown in Figure 8.

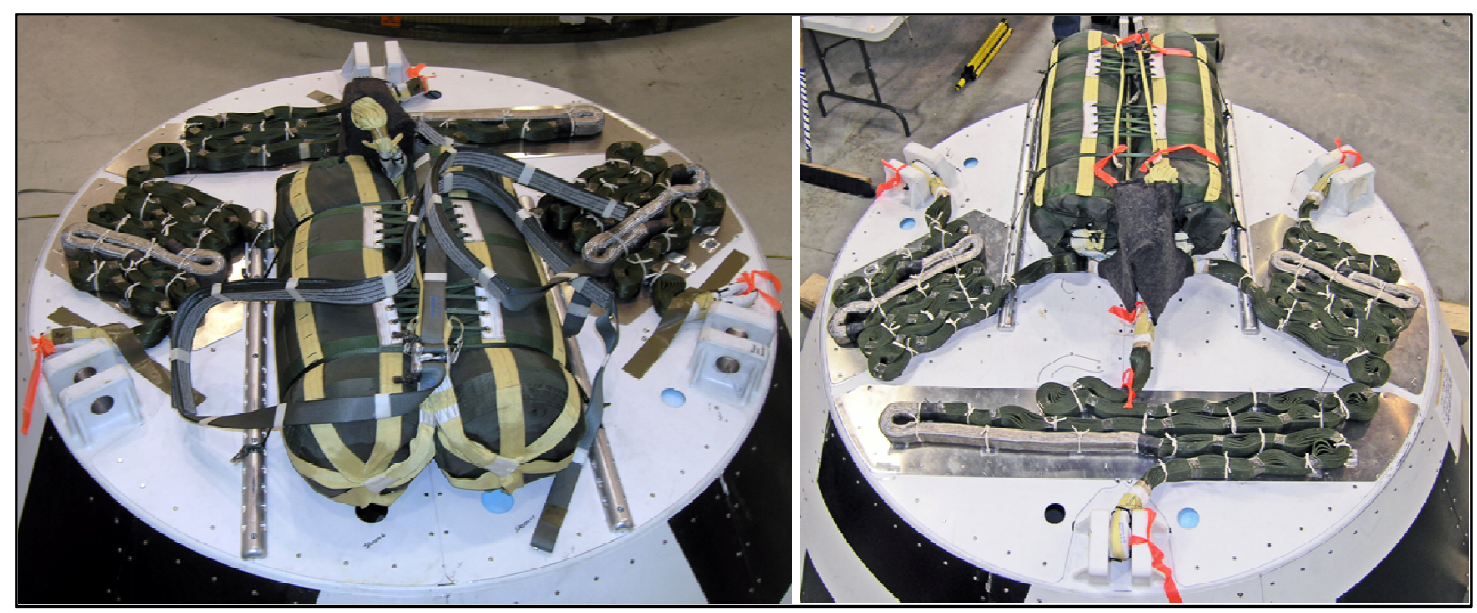

Figure 8. FBC Drogue Installation

Finally, integration of the main parachutes into the underside of the FBC was complicated by interference between the standard (Rev. D) aerial delivery deployment bag and the upper avionics shelf. This interference was resolved by utilizing newer (Rev. E) G-12 low-volume deployment bags. The Rev. D deployment bag is a loose hand pack designed to be quickly repacked with a minimum of equipment, while the Rev. E deployment bag is smaller and requires a modest amount of pressure packing. The Rev. E deployment bags provided 1 to 2 inches of clearance with the avionics shelf. The deployment bags were rigged on end in the FBC, with no rigid parawalls. The parachutes were anchored in place entirely with Kevlar and Nylon soft goods to FBC structural elements. The main parachutes are shown stowed in the FBC in Figure 9.

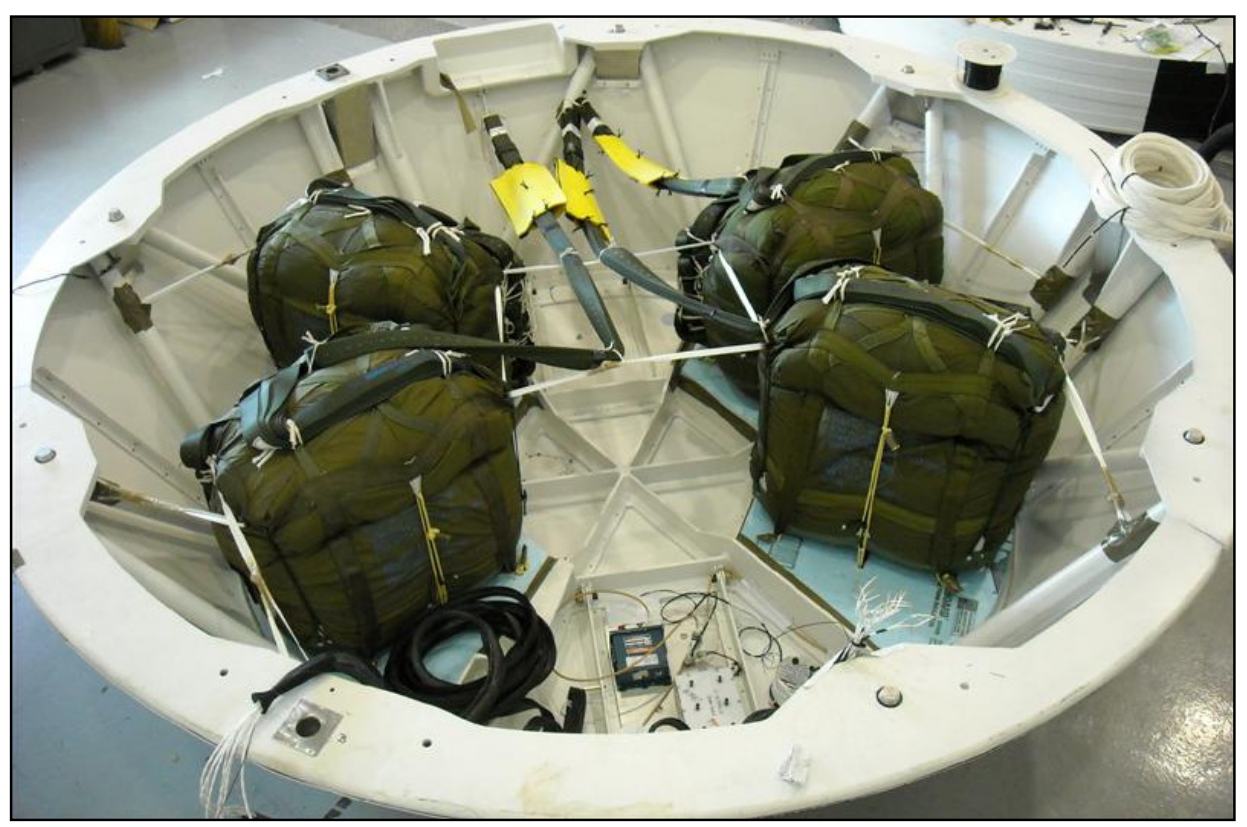

Figure 9. CM Main Parachute Rigging in FBC

American Institute of Aeronautics and Astronautics 


\section{Risk Reduction Testing}

Three major tests were performed to reduce the flight test risk: ground deployment testing of the fairing bridle legs; a static mortar firing; and a system-level drop test of the LPD.

Ground deployment testing of the fairing harness legs was accomplished using a full-sized partial mockup of the forward fairing. Four low-speed static deployment tests were conducted over the range of expected angle of attack (AoA) and yaw angles to prove the orderly deployment of the bridle legs and confluence fitting. The fairing mockup was pitched to the required AoA and rotated to the required yaw angle, then a drogue riser simulator pulled with a truck to deploy the confluence fitting and bridle legs. Only a single drogue riser was simulated to reflect a worst-case condition where one drogue was leading by a large margin so that only a single drogue would cut the confluence retention donut tie.

After completion of the low speed tests, two of the tested attitudes were chosen to test in the high-speed dynamic deployment tests. The confluence fitting was accelerated out of its tray in these tests by means of a bungee cord stretched between a truck and an anchor point. A three-ring release was used to release the bungee from the anchor and transfer the force into the riser simulator. A sketch of the test set-up is shown below in Figure 10.

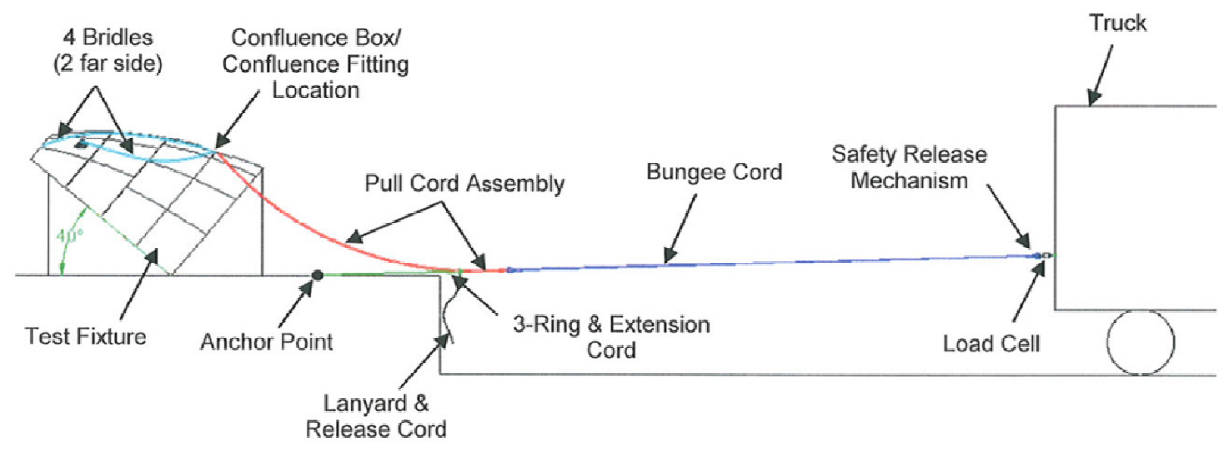

Figure 10. Dynamic Deployment Test Configuration

Both the low-speed static and high-speed dynamic deployment tests proved useful in verifying the orderly deployment of the confluence and bridle legs, as well as providing experience in rigging the reorientation system to the fairing.

One of the particular areas of concern for the mortar system was deployment of the mortar through the OML closeout materials. In order to reduced the risk of adverse interaction between the drogue parachute pack and the closeout materials, another full-sized partial mockup of the forward fairing was utilized. The drogue mortar was mounted in the fairing with flight-like closeouts to the fairing. Mortar firing was captured with a 5,000 fps video camera. Frames from this video are shown in Figure 11.

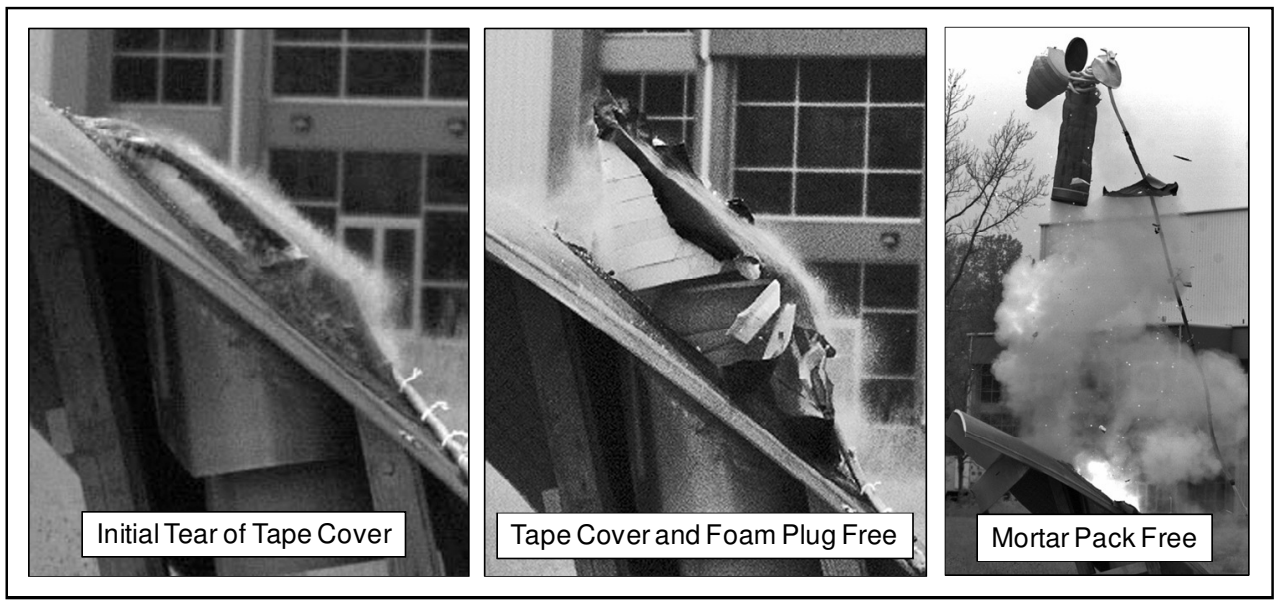

Figure 11. Mortar Test Firing Through OML

American Institute of Aeronautics and Astronautics 
The LPD system-level drop test was conducted to prove the main parachute deployment technique and verify that the main parachutes would survive the structural loads imparted during deployment in the flight test. Additionally, this test would prove the separation of the FBC from the CM boilerplate. The FBC used for this test was identical to the flight FBC, however the CM boilerplate was simulated with a mass simulator only that duplicated the mass, main parachute attachment, and FBC separation joint as the CM boilerplate. No attempt was made to simulate the CM OML or moments of inertia. Because flight drogues were unavailable for this test, the FBC drogues were simulated with a single programmer parachute. The drop test was conducted on March 7, 2009, at the NASA Wallops Test Range. The drop test vehicle (DTV) was release from a CH-53E helicopter at approximately 2,300 $\mathrm{ft}$ MSL. The programmer was static-line deployed and the FBC released from the CM mass simulator 5.4 seconds after release from the helicopter. Deployment of the main parachutes was successful and both the FBC and CM mass simulator landed under good canopies. Figure 12 shows the deployment of the main parachutes from the FBC during this test.

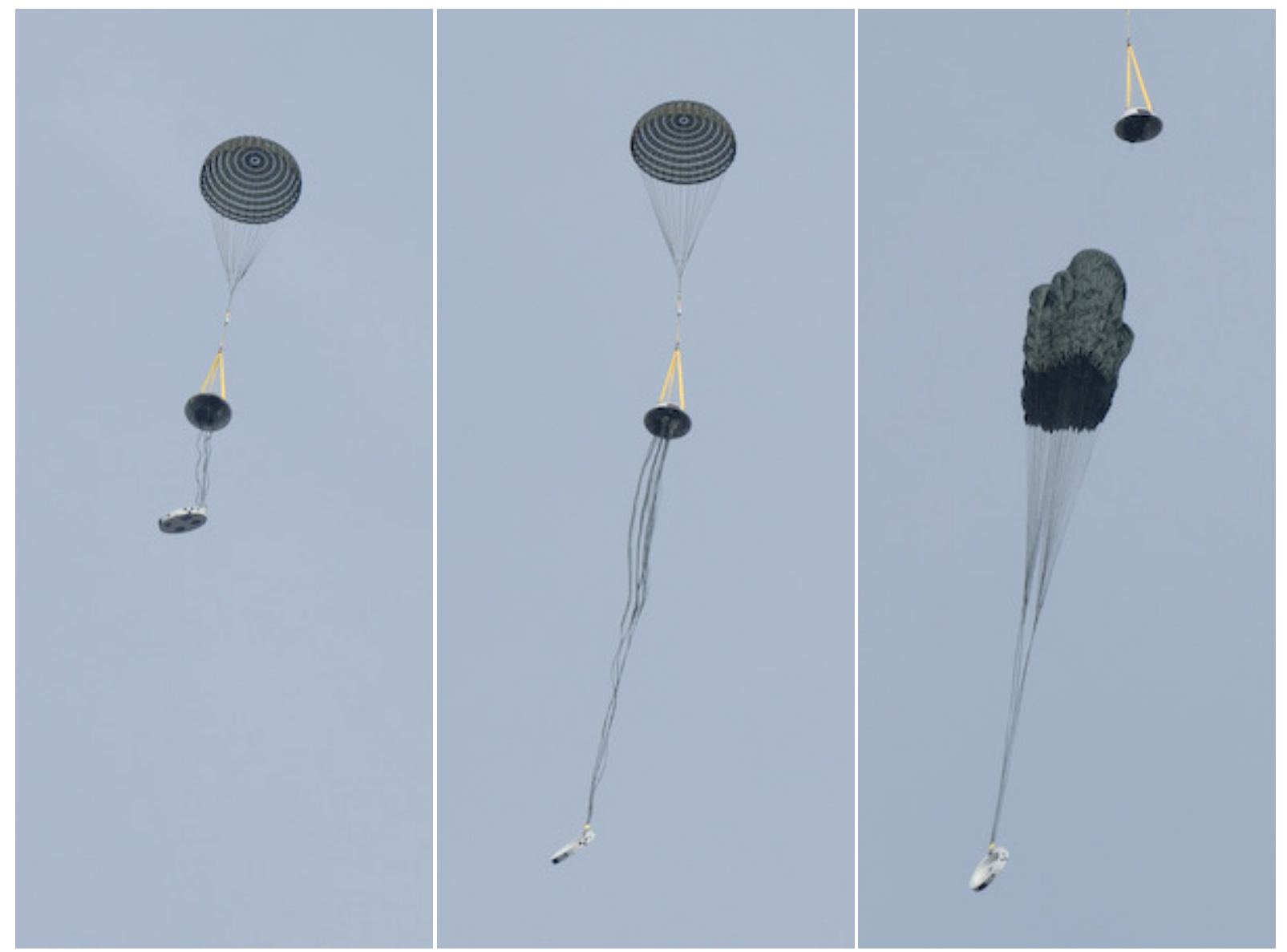

Figure 12. G-12 Deployment from FBC

\section{Discussion of Flight Test Results}

The MLAS mission was flown on the morning of July 8, 2009. The flight was highly successful, with the primary mission objectives of rocket flight, fairing reorientation under parachutes, and clean separation of the CM and fairing all having been met. Further the recovery of the CM under drogue and main parachutes was also very successful. The following presents an overview of some of the data highlights from the flight.

Figure 13 provides a view of the planned separation between the coast skirt and the fairing re-orientation parachutes. As is shown in Figure 14, this separation was easily met in the flight test, based on the planned firing delay and detailed trajectory analysis of potential dispersions. 


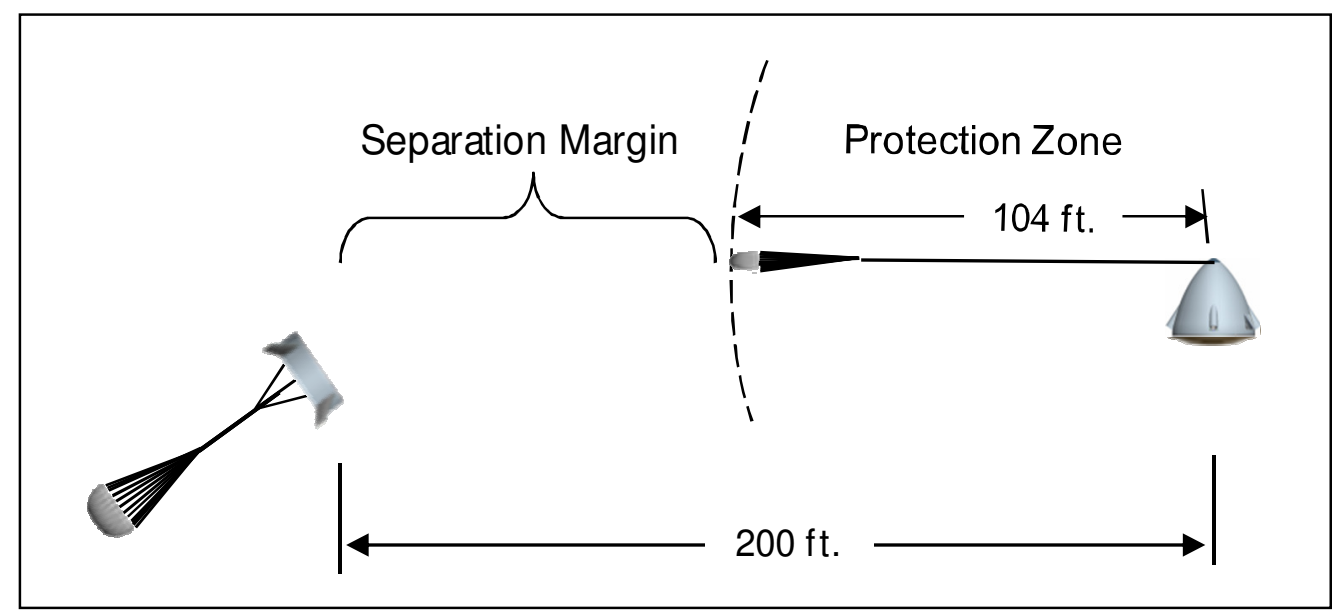

Figure 13. Coast Skirt to Fairing Re-orientation Separation Plan

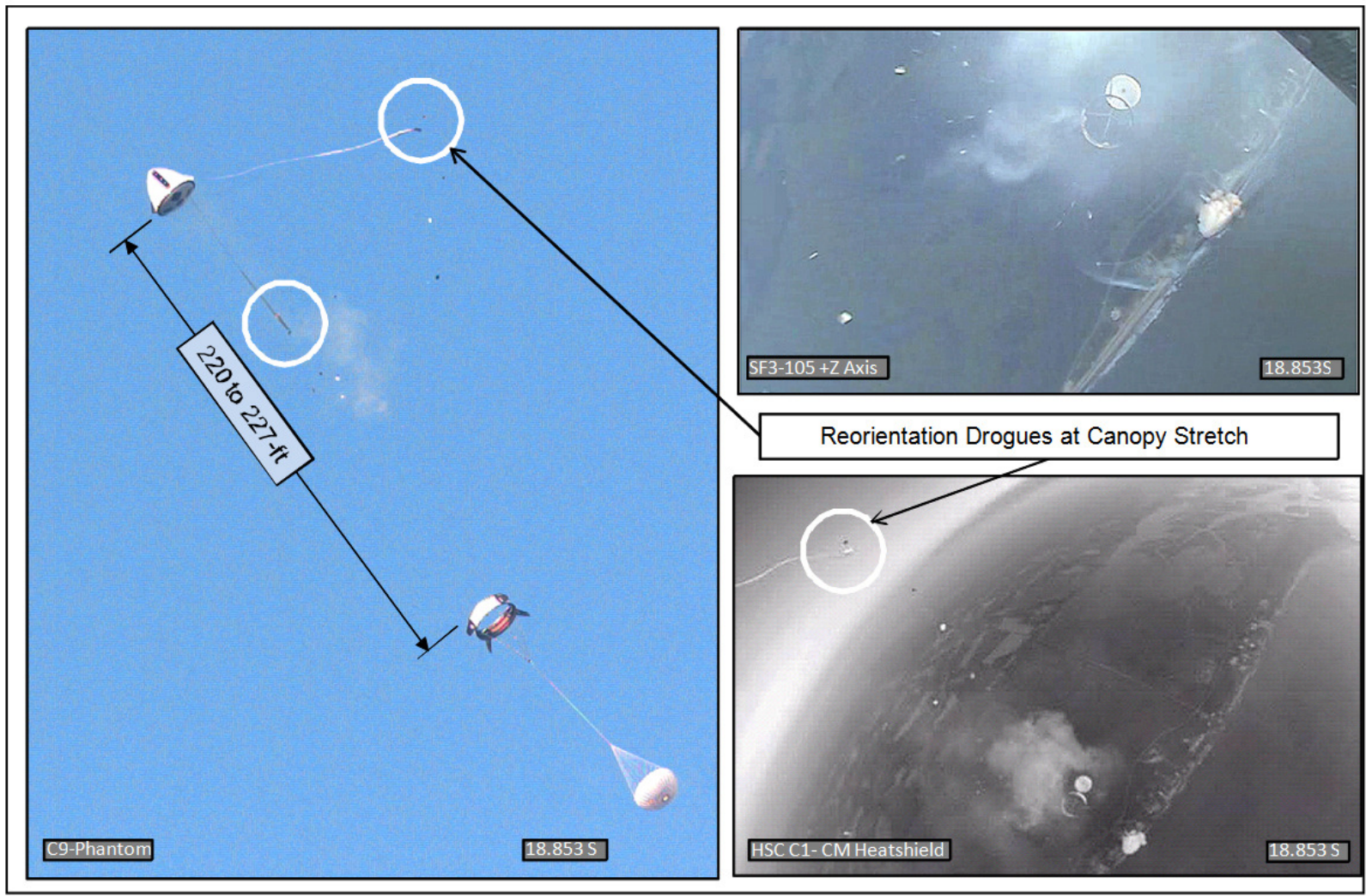

Figure 14. Flight Result, Coast Skirt and Re-orientation Parachute Positions

Figure 15 and Figure 16 present the flight results of the parachute re-orientation of the fairing/CM boilerplate combination. This reorientation maneuver and subsequent stabilization of the fairing prior to CM release was the prime goal of the flight test, and as illustrated in the figures was very successful. Basic fairing/CM motion damped to acceptable limits in about 20 seconds, which was similar to trajectory simulation predictions. Successful damping was critical to the next event, which is the release of the CM boilerplate without significant contact with the other flight items. 

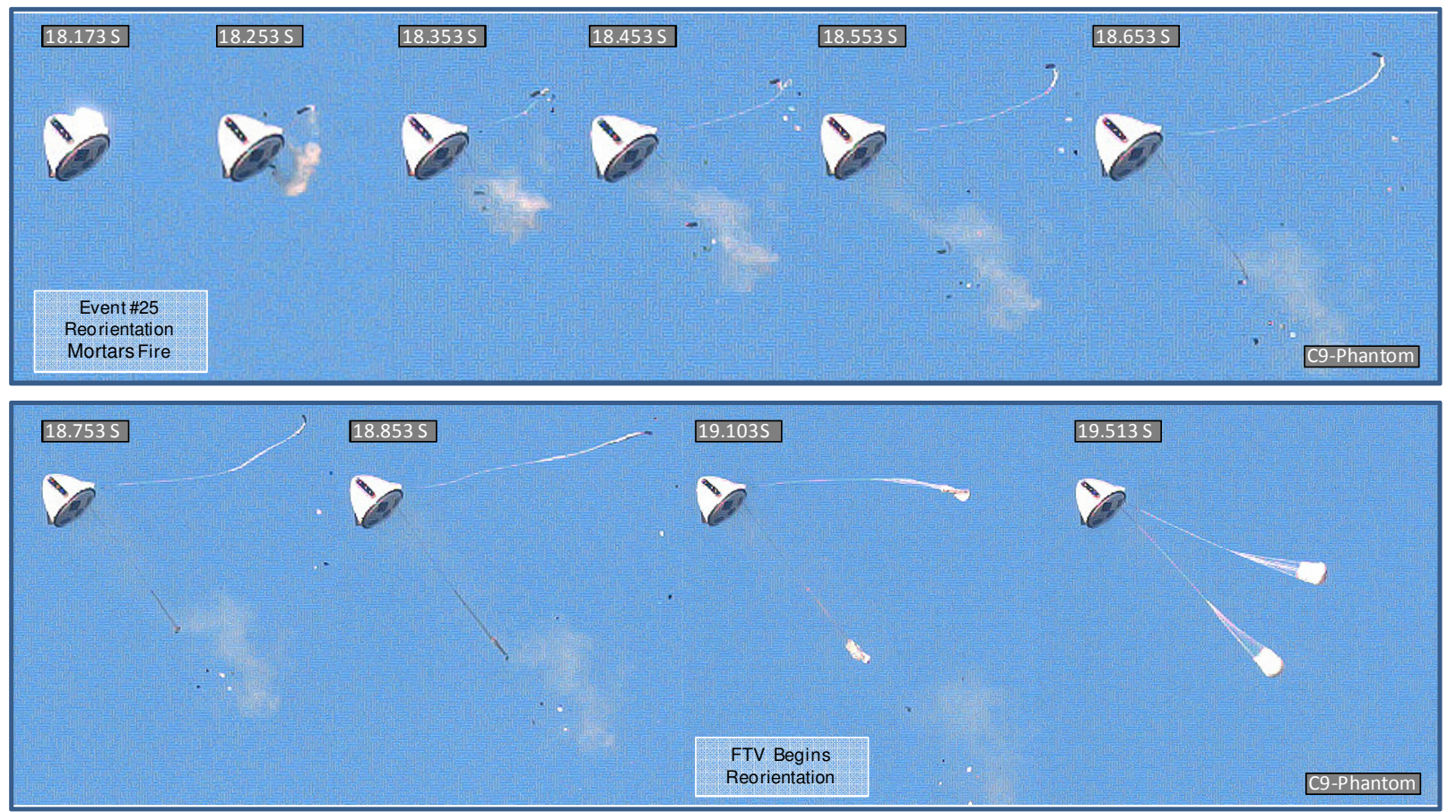

Figure 15. Deployment of the Fairing Re-Orientation Parachutes

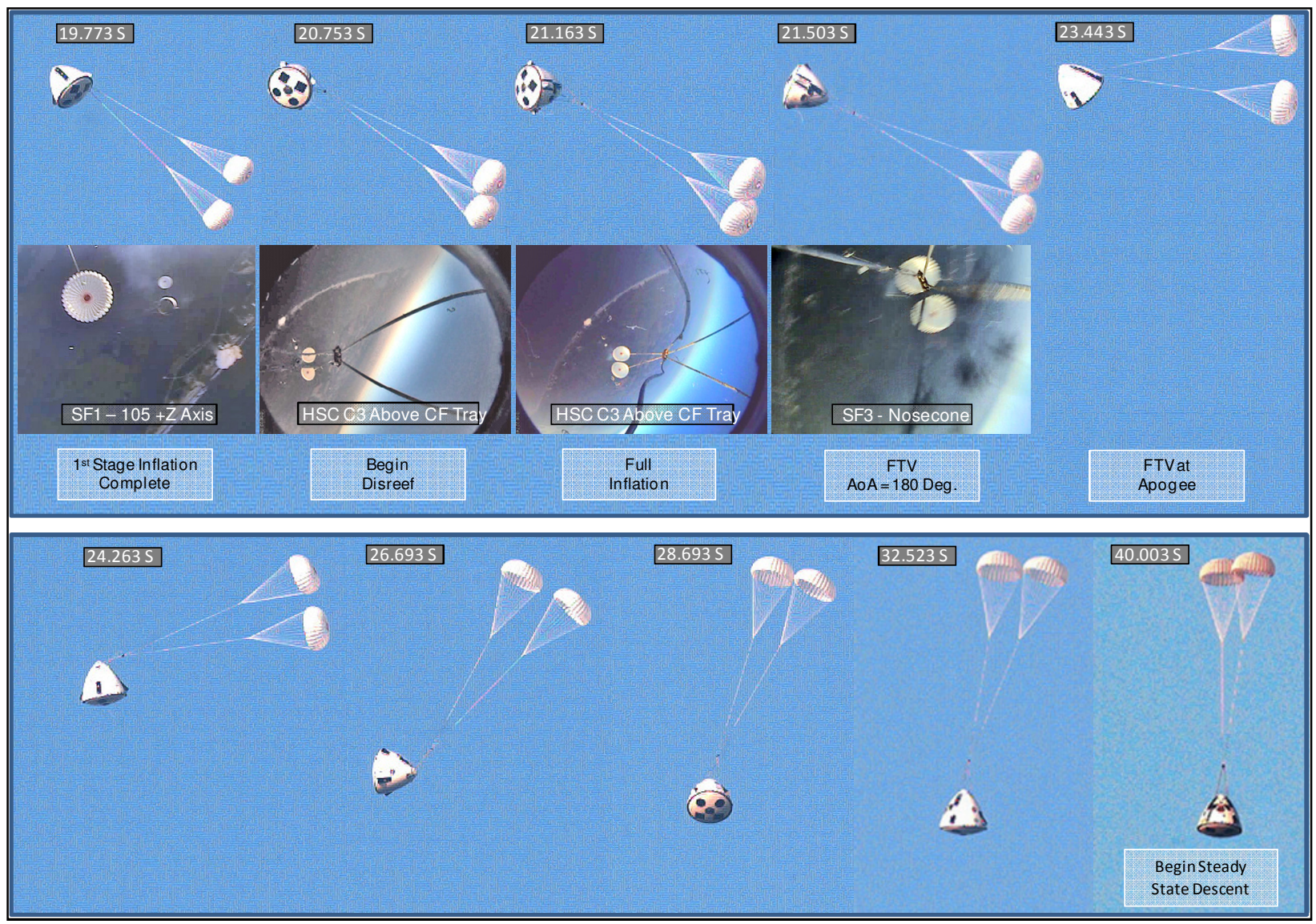

Figure 16. Re-orientation of the Fairing and CM Boilerplate

American Institute of Aeronautics and Astronautics 
Figure 17 presents a sequence from the CM $27.6 \mathrm{ft} \mathrm{D}_{\mathrm{O}}$ VPCR drogue parachute deployment. The main parachute deployment sequence is depicted in Figure 18.

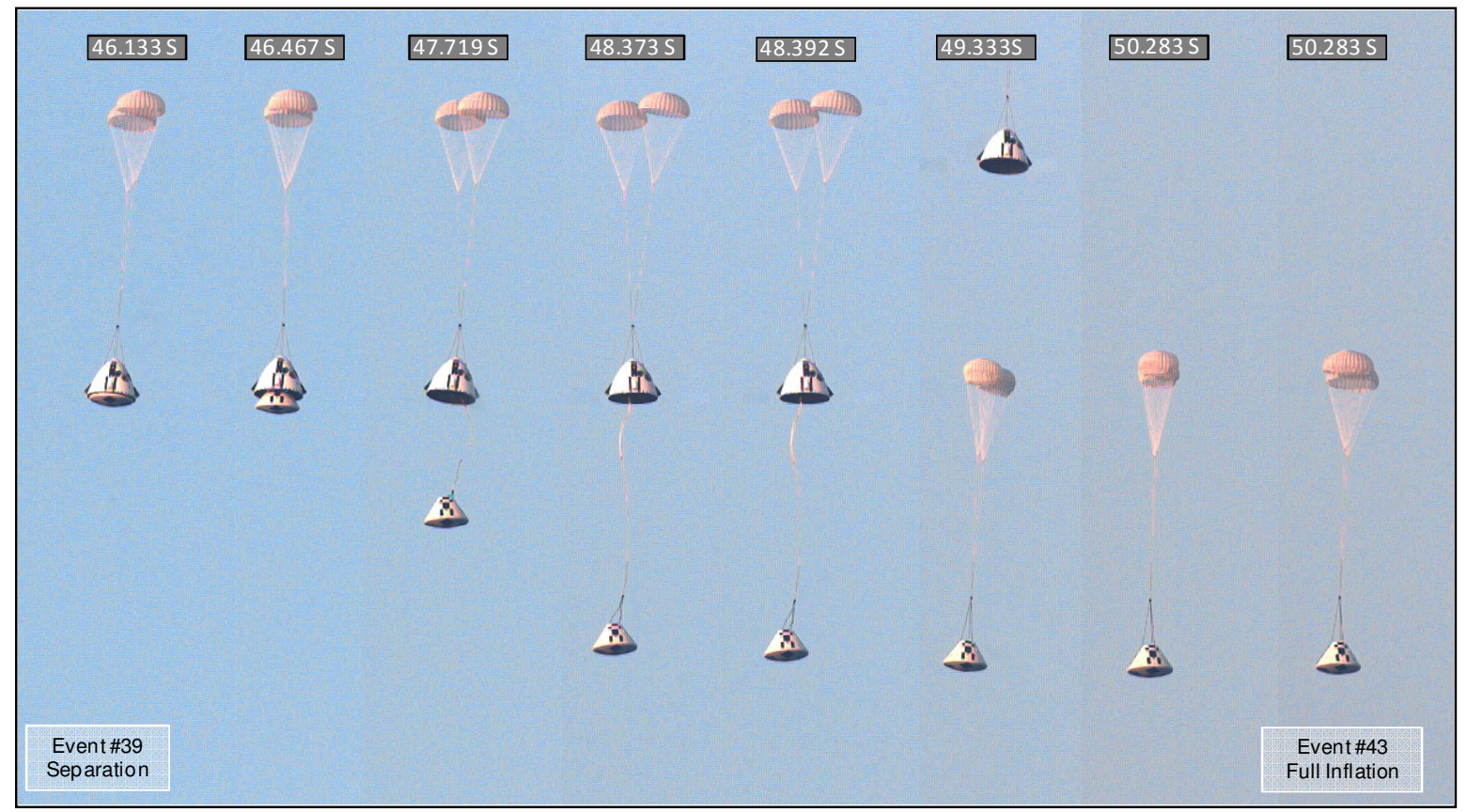

Figure 17. CM Drogue Parachute Deployment

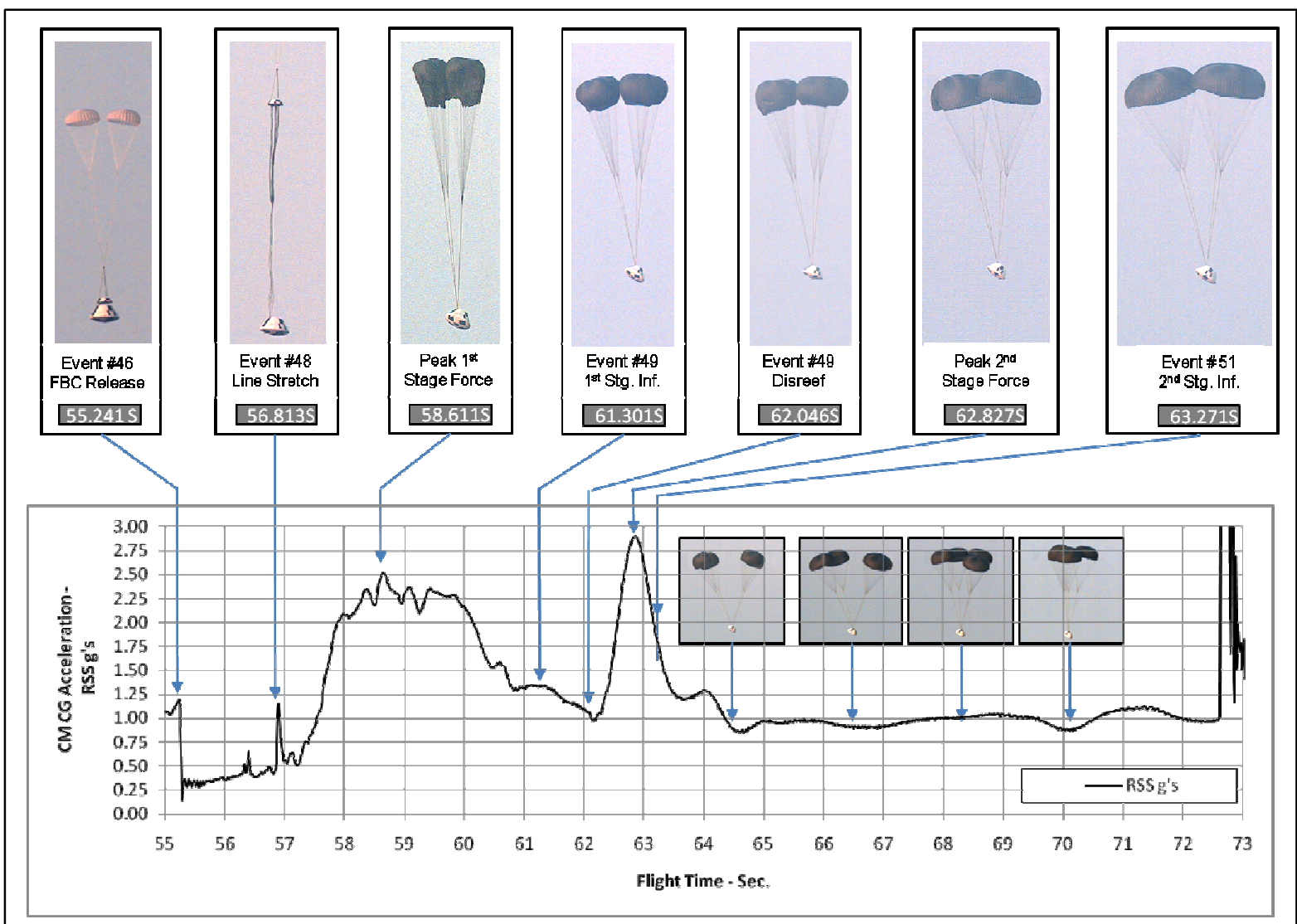

Figure 18. CM Recovery Parachute Sequence

American Institute of Aeronautics and Astronautics 


\section{Conclusion}

The MLAS flight test employed nine parachutes total; five were $27.6 \mathrm{ft} \mathrm{D}_{\mathrm{O}}$ VPCR parachutes with heritage as a spin/stall recovery parachute, and the remaining four were G-12 parachutes with a reefing modification that has extensive air launch target heritage. This level of commonality in the parachutes and usage of proven systems are two key strategies employed in the MLAS program to quickly design, build, and test the MLAS system concept with a minimum of risk. The technical challenges encountered were typical for a rapid response project and all proved solvable. Although the flight test vehicle does differ from the objective system, careful consideration has been given to ensuring that the concept of operation of the reorientation maneuver has not been significantly changed. 